\title{
The Impact of Anxiety in Children on the Autism Spectrum
}

\section{Dawn Adams and Lisa-Marie Emerson}

\begin{abstract}
The recognition of anxiety as one of the most commonly co-occurring diagnoses for individuals on the autism spectrum has led to increased research on symptomatology and treatment, but there is limited research documenting the impact of this anxiety. To address this, this study reports on the Child Anxiety Life Interference Scale (CALIS, parent version) in a community sample of 121 parents of children on the autism spectrum. Scores indicate that the anxiety is impacting upon the child's engagement in activities both in and outside of home as well as impacting upon parent life. Explanatory variables differed for CALIS subscales. As the child's difficulties with uncertainty and parent level of anxiety were the variables that explained the most variance, these may be important foci for effective interventions.
\end{abstract}

Keywords: autism, anxiety, mental health, uncertainty, impact 


\section{The Impact of Anxiety in Children on the Autism Spectrum}

Autism spectrum disorder is a neurodevelopmental condition with a current prevalence estimate of one in 59 children (Baio et al., 2018). The DSM-5 diagnostic criteria (American Psychiatric Association, 2013) describe differences or difficulties with social communication and the presence of restricted and repetitive behaviours. In addition, it is now well recognised that children on the autism spectrum experience elevated levels of anxiety. Meta-analyses reveal that $40 \%$ of children on the spectrum meet the criteria for at least one DSM-IV anxiety disorder (van Steensel et al., 2011), with a further 30-40\% demonstrating subclinical anxiety levels that impact upon daily functioning (Strang al., 2012; Vasa et al., 2013). These anxiety levels are greater than those of neurotypical children, children with externalising problems, and children with other developmental problems, with these differences increasing with age (van Steensel \& Heeman, 2017).

Given this recognition of the elevated prevalence of anxiety in autism, it is understandable that research into this area has increased tenfold over the past decade (Vasa, Keefer, Reaven, South $\&$ White, 2018). Earlier research tended to focus upon identifying anxiety levels and diagnostic rates in autism using measures developed for typically developing children, such as the Anxiety Disorders Interview Schedule - Child and Parent Interview Schedules (ADIS-IV-C/P; Silverman \& Albano, 1996) and the Spence Children's Anxiety Scale - Child and Parent Forms (SCAS-C/P; Spence, 1998). Although these measures are able to capture a DSM-consistent presentation of anxiety (described as a "typical presentation" of anxiety), there is a suggestion that individuals on the spectrum may also show an "atypical" presentation (Kerns \& Kendall, 2012). Furthermore, these standardised assessments are frequently associated with poor reliability when used to measure anxiety in children on the spectrum (e.g., Toscano et al., 2020; van Steensel et al., 2013). Taken together, these limitations highlighted a need for autism-specific measures of anxiety, such as the Anxiety Scale for Children - Autism Spectrum Disorder (ASC-ASD; Rodgers et al., 2016). 
Alongside research focussed upon anxiety presentation and measurement in children on the spectrum, there have also been trials of treatments for anxiety, predominantly cognitive-behavioural therapy (CBT). Meta-analyses have reported positive effects for treating anxiety with CBT in children who are cognitively able to access it, with moderate effect sizes on parent and self-report questionnaires for individuals with "high-functioning autism", $(g=-0.71$; Ung et al., 2015). However, the authors of this meta-analysis did not define what they classified as "high-functioning" nor did they report on any analysis of effect size by IQ or other measure of ability.

Anxiety disorders have a negative impact on children's physical health (e.g., Gurmanken Levy et al., 2007), social development (de Lijster et al., 2018), and academic attainment (Woodward \& Fergusson, 2001) As such, anxiety disorders are now recognised as one of the top 10 contributors to the global burden of disease for young people (Kyu et al., 2016). Whilst knowledge around symptomatology and treatment of anxiety in autism has progressed somewhat in recent years (e.g., Lang et al., 2010; van Steensel et al., 2013), there has been very little research exploring the impact of anxiety on children on the autism spectrum. Of this limited research, anxiety in autism has been repeatedly associated with poorer quality of life. An association between higher anxiety and poorer quality of life has been described in qualitative studies with parents (Ozsivadijan et al., 2012) and with adults on the spectrum (Smith et al., 2019). Quantitative analyses using parent questionnaire data have shown that children on the spectrum with elevated anxiety levels experience poorer quality of life than those with lower levels of anxiety (van Steensel, Bogels, \& Dirksen, 2012). Moreover, anxiety symptoms are a stronger predictor of quality of life than autism characteristics, as determined using both parent (Adams, Clark, \& Simpson, 2020) and self-report data (Adams, Clark, \& Keen, 2019). Although using the total scores on these scales highlights the important link between quality of life and anxiety for children on the spectrum, examining the individual subscales can provide a more nuanced understanding of these relations. For example, using parent-reported data, Adams, Clark \& Simpson (2020) reported that the Anxious Arousal and Separation Anxiety subscales of the ASC-ASD predicted the Emotional Functioning health-related quality of life subscale on the 
Pediatric Quality of Life inventory (PedsQL; Varni et al., 2001). However, only the Anxious Arousal ASC-ASD subscale predicted the PedsQL school functioning subscale. This, and other research exploring the impact of anxiety on psychosocial outcome variables (e.g., Adams \& Emerson, 2020), has indicated the specificity of the relationship between anxiety and impact. Thus, it is important to explore the statistical relationships at subscale rather than total score level.

Whilst the studies discussed above are informative, they focus only upon the association between anxiety and quality of life. To understand better how anxiety affects children on the spectrum, it is important to determine its influence on the child's daily functioning. When asked in interviews, parents have noted that anxiety impacts upon their child across home, social, and school setting (Simpson et al., 2020). The areas of impact described by parents included concentration, learning, behaviour, and the child's ability to perform to the best of their abilities (Simpson et al., 2020). In typically developing children, questionnaires have been developed to measure and describe the extent and type of impact and interference that anxiety has upon the child and their family members. One such measure is the Child Anxiety Life Interference Scale (CALIS; Lyneham et al., 2013), which explores the impact and interference that anxiety has on the child's life (inside and outside the home) as well as on the family. Upon initial description in neurotypical children, Lyneham et al. (2013) reported good internal consistency, moderate-to-high test re-test reliability, significant inter-rater reliability, and good convergent and divergent validity. Scores on this measure also significantly reduced (indicating reduced life interference) following both child-focussed and parent-mediated anxiety interventions (Escovar et al., 2019; Morgan et al., 2016). Differences on the CALIS scores have been noted between neurotypical children with and without a clinical diagnosis of anxiety, as well as between males and females (Lyneham et al., 2013).

To our knowledge, only one published study has used this measure with children on the spectrum. From a sample of 30 children on the spectrum (aged 10-12 years), den Houting, Adams, Roberts and Keen (2020) obtained both parent- and child-reported CALIS data. In general, parents tended to report a greater impact of anxiety on life than did the children. Despite this, all but two 
children (93\%) reported that they were upset by their fear or worries at least sometimes. These findings indicated that both parents and children perceived that anxiety had an impact on school performance. The majority (87\%) of parents reported that their child's classroom performance was impacted by anxiety at least sometimes ( $43 \%$ of parents indicating that this occurs "a great deal"). The most endorsed item on the self-report questionnaire indicated that $57 \%$ of children at least sometimes experienced difficulty completing schoolwork due to anxiety. Further to this, parents reported their stress levels to be impacted by their child's anxious symptomatology (total agreement: $83 \%$ ). For both parent- and child-report data, den Houting et al. reported that overall CALIS scores were significantly correlated with anxiety symptoms (measured on the Spence Child Anxiety Scale); higher levels of anxious symptomatology were associated with higher levels of anxiety-related life interference. This study provides an initial understanding of the impact of anxiety on the daily function of children on the spectrum; however, it only reported on a narrow age range and a relatively small sample. As such, it was not possible to see if anxiety levels predicted of CALIS scores, nor was it possible to statistically control for other factors which may have influenced impact ratings, such as parent anxiety or levels of autism characteristics. Further work is needed with larger samples across a broader age range in order to develop a better understanding of the impact that anxiety is having for children on the spectrum. An understanding of what aspects of anxiety, if any, predict specific areas of life interference may indicate important targets for intervention. The aims of this study were therefore to (a) document parental perceptions of the impact of anxiety in children on the autism spectrum as measured by the CALIS, and (b) identify whether child or parent anxiety symptoms significantly predict (explain significant variance in) the level of impact of the child's anxiety.

\section{Methods}

Ethical clearance for this study was granted through the Griffith University University Human Research Ethics Committee, approval number 2018/509.

\section{Recruitment Procedures}


Parents of children on the autism spectrum were recruited through a social media post via the research centre account. This post was shared by individuals and organisations, thus snowballing the advertisement of the study. Upon clicking through to the online survey centre, participants were presented with an information sheet which described the voluntary and confidential nature of the survey. Participants were informed that completion of the survey was taken as consent to participate. In order to recruit participants with a range of anxiety levels and symptomatology, no inclusion or exclusion criteria were set in relation to the child's anxiety.

In total, 167 parents began the questionnaire. Of these, 17 parents were excluded as they did not provide complete data on the Social Communication Questionnaire (SCQ; Rutter et al., 2003) a measure of the child's autism characteristics. A further five parents were excluded because they had not provided scoreable data on the outcome measures within this study. Of the remaining 145 parents, ten were excluded as the child's SCQ score was below the cut-off indicative of autism (< 15), nine were excluded as their child was aged eighteen years or above and five were excluded as their child was below the age of 5 years (the youngest age at which the ASC-ASD has previously been used) or the child's age was not provided.

\section{Participants}

The final sample consisted of data from parents/guardians (hereafter referred to as parents) of 121 children on the autism spectrum aged from 5-17 years $($ mean $=10.6, S D=3.2)$. The children were predominantly male (66.1\%). All but four children were reported to live full-time with the parent completing the questionnaire; the other four children had shared parental custody arrangements but lived with the parent completing the questionnaire for at least half of the week. Parents were asked whether their child had received any formal diagnoses of the following: speech and language disorder (43.0\% diagnosed), attention deficit disorder/attention deficit hyperactivity disorder (43.8\% diagnosed), anxiety (81.8\% diagnosed), or intellectual disability (14.9\%). Based on parent-report, 88 children $(72.7 \%)$ were reported to be taking medication or supplements, the most common of which was melatonin (31.4\% of sample). 
Informants were mostly mothers $(n=104,85.9 \%)$. Six $(5.0 \%)$ respondents were fathers, seven $(5.8 \%)$ described themselves as "parent", one $(0.8 \%)$ as a "carer" and three $(2.5 \%)$ were grandparents with legal guardianship. Informants' ages were distributed across the age range; 33.9\% aged $21-40$ years, $55.9 \%$ aged $41-50$, and $9.9 \%$ aged 51 or above. Four (3.4\%) parents reported having a diagnosis of an autism spectrum disorder and $46(38 \%)$ reported having received a diagnosis of a mental health difficulty at some point in their lifetime. The majority of the respondents reported having at least a tertiary education (77.7\%) and having a family income in excess of AUD $\$ 80,000$ (58.6\%). For reference, the 2016 Australian Census reported the median Australian annual family income to be AUD \$90,168.

\section{Measures}

\section{Demographic Characteristics}

These were collected using a parent questionnaire focusing upon child (age, gender, age at diagnosis), parent (education, employment), and household (income) variables.

\section{Autism Characteristic}

The SCQ (Lifetime version; Rutter et al., 2003) consists of 40 questions which ask parents about behaviours that may be indicative of social, communicative, or stereotyped behaviours associated with autism. Each item is answered yes or no. A higher score represents more behaviours which may be characteristic of an autism diagnosis. A recent meta-analysis (Chesnut et al., 2017) concluded that when the SCQ cut-off score of 15 is used, it is an acceptable screening measure for autism spectrum disorder (area under the receiver operating characteristic curve .89).

\section{Child Anxiety}

The Anxiety Scale for Children - Autism Spectrum Disorder Parent Form (ASC-ASD-P) (Rodgers et al., 2016) was derived from the Revised Children's Anxiety and Depression Scale (RCADS, Chorpita et al., 2000) which is a well-validated measure of anxiety designed for typically developing children. The ASC-ASD-P was designed to measure both typical and atypical signs of anxiety which may be experienced by a child on the autism spectrum. Although it was designed for 
children aged 8 and above, it has been used successfully to describe anxiety symptomatology in children on the autism spectrum aged 5 and above (e.g., den Houting et al., 2018b; Keen et al., 2019). This questionnaire consists of 24 items which divide into four subscales: Performance Anxiety (five items; maximum score 15); Anxious Arousal (six items; maximum score 18); Separation Anxiety (five items; maximum score 15); and Uncertainty (eight items; maximum score 24). Parents rated severity of each item on a 4-point scale ranging from 0 (never) to 3 (always). The scale has good validity, reliability, and internal consistency including good concurrent reliability with robust measures of anxiety in the general population (Screen for Child Anxiety Related Emotional Disorders, Birmaher et al., 1999; Spence Child Anxiety Scale, Spence, 1998) (den Houting et al., 2018a; Rodgers et al., 2017). Scores on the ASC-ASD greater than 24 are considered to be a "specific indication of significant anxiety" (Rodgers et al., n.d.).. Within this study, the cutoff score of 24 will be used to indicate elevated anxiety symptomatology. Proportional reduction in mean squared error (PRMSE) values suggest that the subscales add clinical utility above using the total score alone (Adams, Simpson, \& Keen, 2018). In the current study, internal consistency was identified as good to excellent for all subscales based on Cronbach's alpha: Anxious Arousal $\alpha=.88$, Separation Anxiety $\alpha=.86$, Performance Anxiety $\alpha=.89$, and Uncertainty $\alpha=.90$.

\section{Parent Anxiety}

Parents rated the seven anxiety items from the Depression Anxiety Stress Scale (DASS-21; Lovibond \& Lovibond, 1995), a widely used measure of psychological well-being in parents of children on the autism spectrum (e.g., Falk et al., 2014; Henry \& Crawford, 2005). In this study, the DASS anxiety subscale demonstrated good internal consistency $(\alpha=.87)$.

\section{Interference of Anxiety}

The Child Anxiety Life Interference Scale (CALIS; Lyneham et al., 2013) asks parents to rate the interference that anxiety has on the child's life and the life of the parents/family. The 17 items are rated on a 5-point Likert scale: (0) not at all, (1) only a little, (2) sometimes, (3) quite a lot, and (4) a great deal, and items are summed into three subscales: Child at Home (4 items), Child outside Home 
(6 items), and Parent Life (7 items). In the current study, internal consistency was identified as acceptable to excellent for all subscales based on Cronbach's alpha (Child at Home $\alpha=.70$; Child Outside Home $\alpha=.86$; Parent Life $\alpha=.91$ ).

\section{Data Analysis}

Data were screened to ensure they met assumptions of normality. Missing value analysis suggested that any missing data were missing completely at random (Little's MCAR test; CALIS, DASS, ASC-ASD $\left.\chi^{2}(85)=73.6, p=.81\right)$. Missing items were imputed as per the manual (Rodgers et al., nd) for the ASC-ASD (prorating a maximum of one missing item for each subscale). The scoring guidelines do not state the procedure for missing data of the CALIS, so this was not imputed. Only two participants had any missing data on the CALIS, but they remained in the study as they both had at least one scoreable CALIS subscale.

Firstly, descriptive statistics were used to describe the frequency with which items were endorsed on the CALIS reported by the parent participants within this sample. Second, the relationship between anxiety life interference (CALIS) scores and sample characteristics, including child gender, caregiver age, and family income, were explored using t-tests and Pearson's correlations. Finally, to study whether child anxiety, parent anxiety, autism characteristics, or child age were explanatory variables for the CALIS subscale(s) and total scores, a series of linear (hierarchical multiple regression $[\mathrm{HMR}]$ ) analyses were conducted. The CALIS subscales were entered as the dependent variables, with ASC-ASD-P subscale scores, DASS anxiety score, SCQ total score, and demographic factors entered as explanatory variables. The contribution of significant variables $\left(\mathrm{sr}^{2}\right)$ was calculated by squaring the semi-partial correlation coefficient of the variable. Alpha was set to .05 for all analyses.

Prior to examining prediction models, bivariate and point-serial correlation analyses were conducted. These revealed no collinearity of explanatory variables $(r>.80)$, thus all were retained (see Table 1). 


\section{Table 1}

Pearson Correlations Between Predictor Variables

\begin{tabular}{|c|c|c|c|c|c|c|c|c|c|c|}
\hline & $\begin{array}{l}\text { Mean } \\
(\mathrm{sd})\end{array}$ & 2 & 3 & 4 & 5 & 6 & 7 & 8 & 9 & 10 \\
\hline 1. SCQ total score & $26.6(6.1)$ & .01 & .14 & .15 & $.32 * *$ & .17 & .11 & .16 & $.25^{*}$ & $.26^{*}$ \\
\hline 2. ASC-ASD-P Performance & $9.3(4.6)$ & - & $.46^{* *}$ & $.35^{* *}$ & $.49 * *$ & $.22 *$ & .03 & $.28^{*}$ & $.25^{*}$ & .08 \\
\hline 3. ASC-ASD-P Anxious Arousal & $7.1(4.3)$ & & - & $.58 * *$ & $.62 * *$ & .10 & .18 & $.44 * *$ & $.35^{* *}$ & $.38 * *$ \\
\hline 4. ASC-ASD-P Separation & $7.5(4.1)$ & & & - & $.67 * *$ & -.07 & $.29 * *$ & $.43 * *$ & $.37 * *$ & $.41 * *$ \\
\hline 5. ASC-ASD-P Uncertainty & $16.0(5.7)$ & & & & - & .05 & $.21^{*}$ & $.44 * *$ & $.57 * *$ & $.49 * *$ \\
\hline 6. Child age (months) & $127.2(38.9)$ & & & & & - & $-.18^{*}$ & .17 & .14 & -.03 \\
\hline 7. DASS (Parent anxiety) & $4.5(4.3)$ & & & & & & - & $.26^{*}$ & .15 & $.42 * *$ \\
\hline 8. CALIS Child at Home & $10.7(3.2)$ & & & & & & & - & $.55^{* *}$ & $.54 * *$ \\
\hline 9. CALIS Child outside home & $14.2(4.9)$ & & & & & & & & - & $.43 * *$ \\
\hline 10. CALIS Parent Life & $20.3(6.6)$ & & & & & & & & & - \\
\hline
\end{tabular}

$* p<.05 ; * * p<.001$ 


\section{Results}

\section{Phenomenology of anxiety symptomatology}

Total ASC-ASD-P scores ranged from 6-70. The average total ASC-ASD-P was 39.9 (SD = 15.1) which equates to a mean score per question of $1.6(\mathrm{SD}=0.63)$. In-line with the parent ratings of clinical diagnoses of anxiety, $102(84.3 \%)$ of parent ASC-ASD-P scores placed their child in the range for "elevated anxiety". The subscale averages (mean score per question) were 1.9 (SD = 0.9) for Performance Anxiety, 1.2 $(\mathrm{SD}=0.72)$ for Anxious Arousal, 1.5 $(\mathrm{SD}=0.29)$ for Separation Anxiety and $2.0(\mathrm{SD}=0.71)$ for Uncertainty.

\section{Phenomenology of Anxiety Life Interference}

Table 2 presents the frequency of endorsement for each item on the CALIS. All parents reported that their child's anxiety impacted upon at least two areas, with the lowest total score being 10. Three parents rated a great deal for all items. The mean score per question for the three CALIS subscales was relatively similar, with the highest being the Parent Life subscale (mean score per question $=2.89, \mathrm{SD}=0.95)$, then Child Outside Home (mean score per question $=2.85, \mathrm{SD}=0.99)$, followed by Child at Home (mean score per question $=2.69, \mathrm{SD}=0.79$ ). 


\section{Table 2}

Means, Standard Deviations, and Proportion of Responses at each Frequency for Each CALIS Item. (for the original CALIS, see Lyneham et al., 2013)

\begin{tabular}{|c|c|c|c|c|c|c|c|}
\hline & & $\begin{array}{l}\text { Not at } \\
\text { all }(\%)\end{array}$ & $\begin{array}{c}\text { Only a } \\
\text { little } \\
(\%) \\
\end{array}$ & $\begin{array}{l}\text { Sometimes } \\
(\%)\end{array}$ & $\begin{array}{l}\text { Quite a } \\
\text { lot (\%) }\end{array}$ & $\begin{array}{l}\text { A great } \\
\text { deal }(\%)\end{array}$ & $\begin{array}{l}\text { Mean } \\
\text { score } \\
(\mathrm{SD})\end{array}$ \\
\hline & $\begin{array}{l}\text { Fears and worries upset or } \\
\text { distress the child }\end{array}$ & 1.7 & 1.7 & 23.1 & 27.3 & 46.3 & $3.2(.95)$ \\
\hline 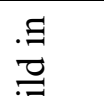 & $\begin{array}{l}\text { Their relationship with } \\
\text { parents }\end{array}$ & 7.4 & 14.0 & 31.4 & 24.8 & 22.3 & $2.4(1.2)$ \\
\hline $\begin{array}{l}\exists \\
0 \\
0\end{array}$ & $\begin{array}{l}\text { Their relationship with } \\
\text { siblings* }\end{array}$ & 3.8 & 11.7 & 38.8 & 24.3 & 21.4 & $2.5(1.1)$ \\
\hline 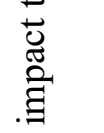 & $\begin{array}{l}\text { Being with friends outside of } \\
\text { school }\end{array}$ & 6.7 & 10.9 & 24.4 & 18.5 & 39.5 & $2.7(1.3)$ \\
\hline$\cdot \stackrel{\mathscr{v}}{\ddot{E}} \ddot{\tilde{y}}$ & Classroom performance & 5.0 & 9.2 & 16.0 & 28.6 & 41.2 & $2.9(1.2)$ \\
\hline 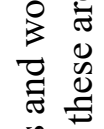 & $\begin{array}{l}\text { Interactions with friends e.g. } \\
\text { at lunch or break }\end{array}$ & 4.2 & 11.8 & 22.7 & 18.5 & 42.9 & $2.8(1.2)$ \\
\hline$\stackrel{\Xi}{\oplus}$ & Playing sport & 7.6 & 10.9 & 19.3 & 21.8 & 40.3 & $2.8(1.3)$ \\
\hline$\frac{\widetilde{U}}{\mathrm{\Xi}}$ & Doing enjoyable activities & 5.8 & 7.4 & 19.0 & 22.3 & 45.5 & $2.9(1.2)$ \\
\hline 虍 & Doing daily activities & 2.5 & 8.3 & 19.0 & 30.6 & 39.7 & $3.0(1.1)$ \\
\hline$\stackrel{\Xi}{\stackrel{\Xi}{\Xi}}$ & $\begin{array}{l}\text { Caregiver relationship with } \\
\text { partner/potential partner }\end{array}$ & 5.8 & 5.0 & 27.3 & 24.0 & 38.0 & $2.8(1.2)$ \\
\hline$\stackrel{\Xi}{ \pm}$ & $\begin{array}{l}\text { Caregiver relationship with } \\
\text { extended family }\end{array}$ & 5.8 & 9.1 & 24.8 & 31.4 & 28.9 & $2.7(1.2)$ \\
\hline$\stackrel{\pi}{\stackrel{\Xi}{\Xi}}$ & $\begin{array}{l}\text { Caregiver relationship with } \\
\text { friends }\end{array}$ & 8.3 & 13.2 & 24.0 & 26.4 & 28.1 & $2.5(1.3)$ \\
\hline $\begin{array}{l}0 \\
0 \\
\vdots \\
0 \\
0\end{array}$ & Caregiver career & 8.3 & 5.0 & 10.7 & 19.0 & 57.0 & $3.1(1.3)$ \\
\hline 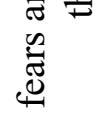 & $\begin{array}{l}\text { Caregiver ability to attend } \\
\text { activities/events without child }\end{array}$ & 5.8 & 10.7 & 17.4 & 17.4 & 48.8 & $2.9(1.3)$ \\
\hline $\begin{array}{l}\frac{8}{0} \\
\frac{0}{0} \\
\stackrel{\Xi}{\Xi}\end{array}$ & $\begin{array}{l}\text { Caregiver ability to attend } \\
\text { activities/events with child }\end{array}$ & 1.7 & 9.1 & 14.9 & 19.8 & 54.5 & $3.2(1.1)$ \\
\hline 高 & Caregiver level of stress & 2.5 & 8.3 & 13.2 & 37.2 & 38.8 & $3.0(1.0)$ \\
\hline
\end{tabular}

*Only reported for children who are reported to have at least one sibling, $n=109$.

The individual items which had the highest mean score, suggesting that anxiety is impacting most upon that activity, were the ability for the caregiver to attend activities or events with the child (mean 
$=3.2 ; 54.5 \%$ of parents rated their child's anxiety as impacting this a great deal) and the caregiver's career (e.g., choice to work, how many hours, or how much work they miss; mean $=3.1 ; 57.0 \%$ of parents rated their child's anxiety as impacting this a great deal).

The items with the lowest mean score, suggesting that anxiety does not impact upon these activities as much as some of the other areas, were the child's relationship with their parents (mean = $2.4 ; 7.4 \%$ of parents rated that their child's anxiety did not at all impact their relationship) and the child's relationship with their siblings (mean $=2.5 ; 6.7 \%$ of parents rated that their child's anxiety did not at all impact sibling relationships).

\section{Clinical Correlates of CALIS Subscale Scores}

There were no significant differences based upon gender of the child for the total score $(t(117)=.47, p=.64)$, Child at Home subscale $(t(118)=0.68, p=.50)$, Child Outside Home subscale $(t(117)=0.53, p=.60)$, or Parent Life subscales $(t(119)=0.37, p=.71)$. There were also no significant differences on the total score $(U=846, Z=5697, p=.78)$, Child at Home subscale $(U=771, Z=$ $.91, p=.36)$, Child Outside Home subscale $(U=855, Z=5706, p=.84)$, or Parent Life subscales $(U$ $=704.5, Z=5754.5, p=.14$ ) between children with and without a co-occurring intellectual disability (based on parent report). Child age, family income, carer age, and carer education level were not correlated with CALIS total or subscale scores $(\mathrm{p}>.05)$.

\section{HMRs of CALIS Subscale Scores}

In order to explore whether specific subscales on the measure of anxiety predict CALIS, three HMRs were undertaken with the CALIS subscales as the outcome variable. As the SCQ score was weakly correlated with some subscales of the CALIS (see Table 1), autism characteristics (which have previously been shown to be predictive of parenting behaviour; Wan et al., 2012) were controlled for by entering the child's total SCQ score in Step 1. At Step 2, the ASC-ASD-P subscale scores were entered using the forced entry/enter method. Finally, at Step 3, parent anxiety (DASS-A) was added. As no demographic characteristics were associated with CALIS scores, these were not controlled for in the analysis. All beta weights, $t$ statistic values for $t$ tests of beta weights, and 
corresponding $p$ values for explanatory variables for each step of each model are displayed in Table 3. All models, except for Step 1 of the Child at Home subscale, were significant, with the significant models predicting $24-40 \%$ of the variance.

Table 3

Hierarchical Multiple Regression Analyses for CALIS Subscale Scores

\begin{tabular}{|c|c|c|c|c|c|}
\hline CALIS subscale & Step & Predictor & $\beta$ Step 1 & $\beta$ Step 2 & $\beta$ Step 3 \\
\hline \multirow[t]{6}{*}{ Child at Home } & 1 & SCQ & .16 & .06 & .05 \\
\hline & 2 & Performance Anxiety & & .05 & .07 \\
\hline & & Anxious Arousal & & $.23 *$ & $.22 *$ \\
\hline & & Separation anxiety & & .18 & .13 \\
\hline & & Uncertainty & & .14 & .14 \\
\hline & 3 & DASS-A & & & .15 \\
\hline$\Delta R^{2}$ & & & & $.24 * * *$ & .02 \\
\hline$R^{2}$ & & & .02 & $.26^{* * *}$ & $.28 * * *$ \\
\hline \multirow[t]{6}{*}{ Child Outside Home } & 1 & SCQ & $.25 * *$ & .09 & .09 \\
\hline & 2 & Performance Anxiety & & -.006 & -.001 \\
\hline & & Anxious Arousal & & .02 & .02 \\
\hline & & Separation Anxiety & & -.02 & -.03 \\
\hline & & Uncertainty & & $.54 * * *$ & $.54 * * *$ \\
\hline & 3 & DASS-A & & & .04 \\
\hline$\Delta R^{2}$ & & & & $.27 * * *$ & .002 \\
\hline$R^{2}$ & & & $.06 * *$ & $.33 * * *$ & $.33 * * *$ \\
\hline \multirow[t]{6}{*}{ Parent Life } & 1 & SCQ & $.26 * *$ & .09 & .08 \\
\hline & 2 & Performance Anxiety & & $-.23 *$ & $-.20 *$ \\
\hline & & Anxious Arousal & & .15 & .14 \\
\hline & & Separation Anxiety & & .12 & .04 \\
\hline & & Uncertainty & & $.40 * *$ & $.39 * * *$ \\
\hline & 3 & DASS-A & & & $.30 * * *$ \\
\hline$\Delta R^{2}$ & & & & $.24 * * *$ & $.08 * * *$ \\
\hline$R^{2}$ & & & $.07 * *$ & $.31 * * *$ & $.39 * * *$ \\
\hline
\end{tabular}


For the Child at Home subscale, the model at Step 1 (SCQ) was not significant $(F(1,118)=$ $2.89, p=.09)$. The addition of ASC-ASD-P subscales at Step 2 resulted in a significant model $(F(5$, $114)=7.99, p<.001)$. The $24 \%$ increase in variance explained $\left(F_{\text {change }}(4,114)=9.1, p<.001\right)$ was predominantly accounted for by the ASC-ASD-P Anxious Arousal score $(\beta=.23)$, with a higher number of physiological symptoms associated with increased impact of anxiety on the child at home. The model at Step 3 (SCQ score, child anxiety, parental anxiety) was significant $(F(6,113)=7.34, p$ $<.001)$ and accounted for an additional but non-significant $2 \%$ of the variance $\left(F_{\text {change }}(1,113)=3.28\right.$ $p=.07)$. The Anxious Arousal ASC-ASD-P subscale $(\beta=.22)$ remained the only significant explanatory variable, explaining $2.6 \%$ of the variance.

For the Child outside home subscale, the model at Step 1 (SCQ) was significant $(F(1,117)=$ $7.81, p=.006$ ). There was a significant $27 \%$ increase in $\mathrm{R}^{2}$ at Step 2, with the addition of the ASCASD-P subscales $\left(F_{\text {change }}(4,113)=11.08, p<.001\right)$. The unique significant explanatory variable was the ASC-ASD-P Uncertainty subscale score $(\beta=.48)$ which explained $11.6 \%$ of the variance. The addition of parent anxiety at Step 3 did not account for any further variance in the model $\left(F_{\text {change }}(1\right.$, $112)=.26 p=.61)$. The full model at Step 3 remained significant $(F(6,112)=9.12, p<.001)$, with the ASC-ASD-P Uncertainty subscale $(\beta=.48)$ being the only significant explanatory variable, continuing to explain $11.6 \%$ of the variance.

For the Parent Life subscale, the model at Step 1 (SCQ) was significant $(F(1,119)=8.66, p=$ .004). There was a $24 \%$ and significant increase in $\mathrm{R}^{2}$ at Step 2, with the addition of the ASC-ASD-P subscales $\left(F_{\text {change }}(4,115)=10.06, p<.001\right)$, with the ASC-ASD-P Uncertainty subscale score $(\beta=$ $.46)$ and Performance Anxiety $(\beta=-.33)$ subscale score accounting for $6.2 \%$ and $3.6 \%$ of the variance respectively. The model at Step 3 was significant $(F(6,114)=12.22, p<.001)$ and accounted for $8 \%$ additional variance from Step $2\left(F_{\text {change }}(1,114)=15.3, p<.001\right)$. The significant explanatory variables were ASC-ASD-P Uncertainty subscale $(\beta=.45)$, Parent Anxiety $(\beta=.46)$, and ASC-ASD-P Performance Anxiety subscale ( $\beta=-.29$ ), explaining $5.8 \%, 8.2 \%$, and $2.7 \%$ of the variance respectively. 


\section{Discussion}

This study is the first to explore the impact and life interferences of child anxiety in a community sample of individuals on the spectrum across the childhood age range. The study also aimed to identify the potential role of child autism characteristics, child anxiety, and parental anxiety on the impact and life interference reported. At least three-quarters of the parents reported that their child's anxiety impacted their child in each area at least sometimes. More than $40 \%$ of parents reported that their child's anxiety impacted their child's ability to do enjoyable activities, interact with their friends and/or their classroom performance a great deal and over half of parents reported that their child's anxiety impacted upon the parent's ability to attend activities or events with their child and the parent's career a great deal. These findings highlight the significant impact that anxiety can have upon children on the autism spectrum and their parents. Thus, more research is required into effective and accessible treatments to prevent and/or reduce anxiety in children on the autism spectrum.

\section{The Impact of Anxiety on Daily Living}

Although not compared statistically, the CALIS scores reported within this sample of parents of children on the spectrum can be interpreted with reference to previous research with samples of typically developing children. Lyneham et al. (2013) reported CALIS scores from typically developing children aged 6 - 17years, 94\% of whom were recruited through anxiety clinics and 93\% of whom had an anxiety disorder or mood disorder diagnosis. Interestingly, the profile and correlates of the results were not very similar between this study and Lyneham et al. (2013). First, the pattern of highest to lowest subscale score differed between the two samples. For the current sample, parents of children on the spectrum rated the impact of anxiety as greatest on family life, then on the Child outside home, and finally, on the child inside the home. In direct contrast, the neurotypical clinical sample of Lyneham et al. revealed the opposite pattern: the greatest impact was reported for the child inside the home, then for the Child outside home, and then for family life. Second, while Lyneham et al. generally found higher CALIS scores in females than males in typically developing children, no 
differences were observed as a function of gender in the current sample. Interestingly, as per the typically developing sample in Lyneham et al., no association was found between CALIS scores and age for children on the spectrum.

Most strikingly was the magnitude of difference in the scores between typically developing children (Lyneham et al., 2013) and the community autism sample reported upon in this study. In the current findings, the Child outside Home subscale score was 1.5 times greater for children on the spectrum, and their Parent Life subscale score was more than twice that of the clinical sample of neurotypical children. These findings indicate a greater impact of anxiety on the life of children on the spectrum compared to typically developing children: The lack of correlation between the CALIS subscales and the SCQ score (see Table 2) observed in the current study suggests that parents were not rating the impact and interference of their child's autism characteristics. The increased impact of anxiety symptomatology in autism can be understood using models of anxiety in autism. One current model has proposed that it is the complexity of interactions between the characteristics of autism (e.g., sensory sensitivities, restricted and repetitive behaviours, specific cognitive profiles), external environmental factors, and anxiety symptomatology (e.g., South \& Rodgers, 2017) that contribute to, impact upon, or interfere with the daily activities of the individual on the spectrum. Further research could measure each variable within this model, as well as the impact of anxiety, to elucidate the nature of the relationships between each factor.

The findings reported here from a community sample highlight that the impact of anxiety is not limited to those with a clinical diagnosis of an anxiety disorder or those presenting to clinical services requesting formal help. The elevated level of impact of anxiety in individuals on the spectrum provides a clear indication of the need to support parents and children on the spectrum with all levels of anxiety. Previous research has reported a wide range of barriers to accessing suitably experienced practitioners, and low satisfaction with mental health services experienced by the autism community. Furthermore, there is a reported lack of confidence of mental health providers to work with individuals on the spectrum (Jackson et al., 2020; Maddox et al., 2019). These factors may 
conspire to mean that many parents and/or children who could benefit from help or support do not seek a clinical diagnosis and/or treatment for their child's anxiety. Exploring alternative ways, such as online self-help materials or workshops (e.g., Cool Little Kids Online; Morgan et al., 2016), may help to provide accessible support to families who are unable or unwilling to attend formal therapy sessions.

More than two-thirds of parents in the current study noted that their child's anxiety has an impact upon their classroom performance quite a lot or a great deal. Two recent systematic reviews (Adams, Young, \& Keen, 2019; Kester \& Lucyshyn, 2018) have noted the limited research on anxiety in children on the spectrum in school settings. This accentuates the clear need to explore the potential impact that anxiety is having on academic performance in children on the spectrum. Whilst a number of studies (e.g., Factor et al., 2017; Kerns et al., 2015; McVey et al., 2018) have examined the impact of anxiety on social outcomes for children on the spectrum, only three have explored its impact on academic outcomes. Of these, two considered the relationship between anxiety and school quality of life (Adams, Clark, \& Simpson, 2020; Adams, Clark, \& Keen, 2019) and one explored test anxiety and mathematics performance (Oswald et al., 2016). Children on the spectrum have been shown to underperform academically compared to their peers, yet no consistent predictors of this academic underachievement have been identified (Keen et al., 2016). Academic success relies not only on academic skills but also on academic enablers such as engagement, motivation, and social skills (DiPerna \& Elliott, 2002). These attitudes and behaviours facilitate students' participation in, and benefit from, academic instruction in the classroom (DiPerna \& Elliott, 2002). Amongst typically developing children, anxiety is a strong predictor of school engagement and performance, with reductions in anxiety leading to improvements in these areas (Wood, 2006). It may be that anxiety impacts upon the skills which enable learning and achievement in school, and thus contributes to the academic underachievement reported in children on the spectrum. Further work is needed within this area to (a) explore whether anxiety is contributing to educational outcomes for 
children on the spectrum, and (b) determine whether interventions to reduce anxiety can impact upon these outcomes.

\section{Predictors of the Impact of Anxiety on Daily Living}

The differential relationship between subscales of the ASC-ASD, the DASS, and the SCQ with each of the subscale scores of the CALIS is important to consider in relation to treatment planning and evaluation. Impact of anxiety in the home was predicted by the child's ASC-ASD Anxious Arousal subscale score (e.g., heart racing, sweaty palms) whereas, the impact of anxiety outside of the home was predicted by the child's ASC-ASD Uncertainty score (needing to be prepared, afraid of new things). These observed differences in relationships may suggest that if the child is most impacted by anxiety in the home setting, it may be important to consider addressing anxious arousal aspects of anxiety. In contrast, if they are most impacted when in the community it may be beneficial to consider addressing the difficulties with uncertainty.

As well as the child's Performance Anxiety and difficulties with Uncertainty, parent anxiety levels were a significant explanatory variable of the Parent Life subscale score, highlighting the importance of considering parental anxiety when supporting anxiety in children on the spectrum. It is well documented that anxiety levels are higher in parents of children on the autism spectrum than in parents of neurotypical children and of children with other developmental disabilities (Schnabel et al., 2020). However, the potential interaction between parental and child anxiety has not been widely acknowledged. Two studies evaluating anxiety CBT treatments for children on the spectrum have reported a reduction in parent anxiety levels from pre-post intervention, but only in the parents of children who responded to the CBT treatment (Conner, Maddox \& White, 2013; Reaven et al., 2015). Parental anxiety may interact with both the impact, and the treatment of, anxiety in children on the spectrum, as it does neurotypical children (Creswell et al., 2008). Future research should explore the treatment of parental anxiety prior to, or concurrent with, adolescent or child treatment in this population. 
When controlling for autism characteristics, there was one subscale of the ASC-ASD, the Uncertainty subscale, which predicted two domain scores of the CALIS: Child outside Home and Parent Life. The ASC-ASD Uncertainty subscale contains a number of questions based upon items in the Intolerance of Uncertainty (IU) scale (Freeston et al., 1994). IU is a broad dispositional factor characterised by the tendency to react negatively to situations and events that are unforeseen or unpredictable (Buhr \& Dugas, 2006). Meta-analyses have identified a strong association between IU and both anxiety and worry in young people and is recommended as a construct to target in treatment (Osmanagaoglu et al., 2018). Not only is IU elevated in individuals on the spectrum, it has also been shown to (at least partly) mediate the relationship between autism characteristics (including sensory sensitivities) and anxiety in children, youth, and adults (Boulter et al., 2014; Hwang et al., 2019; Maisel et al., 2016; Neil et al., 2016). Moreover, previous studies have indicated that IU in children on the spectrum has influenced a wide range of outcomes, including anxiety symptomatology, quality of life (Adams, Clark \& Keen, 2019), family behaviours and accommodation (Hodgson et al., 2017; Adams \& Emerson, 2020). The current study highlights that IU also influences the interference that the anxiety has on the child doing activities outside of the home, and on family life. These emerging findings may suggest that IU has a widespread impact, which highlights the importantance of addressing IU in treatments for anxiety in individuals on the spectrum. One such program targeting this factor is Coping with Uncertainty in Everyday Situations (CUES; Rodgers et al., 2017), which is currently being further explored in a pilot randomised controlled trial (Rodgers et al., 2019).

\section{Limitations and Future Directions}

The current study needs to be considered in light of several limitations. Firstly, and most importantly, although the study used an autism-specific measure of anxiety, the questionnaire exploring life interference is one designed for families of neurotypical children.Given the lack of opportunity for parents to add any additional comments or areas of impact, it is unknown whether this measure adequately captured all the areas of life that anxiety was having an impact for children on the autism spectrum. Secondly, whilst parents are important sources of information and used as 
informants around mental health and autism, they are only one source of information. This study should be repeated with data from children who are able to self-report to explore whether the predictors of areas of impact remain the same or differ between informants.

Whilst using an online survey allowed for a good-sized, community-based sample, it meant that there was no independent verification of the diagnoses of autism or anxiety other than scores on screening measures (SCQ, ASC-ASD). It was also not possible to measure other factors that could have influenced the impact of anxiety, such as adaptive behaviour levels of the child or family factors such as parenting roles or practices. Although there were no differences in the CALIS scores based on the presence or absence of a co-occurring intellectual disability, including an IQ score in regressions would have allowed for a broader exploration of the range of ability on the impact of anxiety. The lack of a control group of neurotypical children limits the extent to which these results can be interpreted as autism specific. Finally, more than $80 \%$ of parents reported that their child had a co-occurring diagnosis of an anxiety disorder and more than $80 \%$ of scores on the ASC-ASD were classified as elevated. This frequency of anxiety disorders is higher than expected, but does align with previous reported "subclinical" rates (Strang al., 2012; Vasa et al., 2013) and aligns with the proportion of parents reporting that their children are significantly impacted by anxiety (Adams, Young, Simpson \& Keen, 2018). The potential influence of the recruitment strategy in the current study is also worthy of note. The use of social media of a research centre with an active research program in anxiety and autism, and the title of the study that parents saw once they clicked through to the information sheet ("How does anxiety in children with autism impact upon daily life?") may have created a possible bias in the sample. 


\section{Compliance with Ethical Standards}

All procedures performed in studies involving human participants were in accordance with the ethical standards of the institutional and/or national research committee and with the 1964 Helsinki declaration and its later amendments or comparable ethical standards.

\section{Informed Consent}

Informed consent was obtained from all individual participants included in the study.

\section{Conflicts of interest}

The authors declare that they have no conflict of interest. No financial support was provided for this study. 


\section{References}

Adams, D., Clark, M., \& Keen, D. (2019). Using self-report to explore the relationship between anxiety and quality of life in children on the autism spectrum. Autism Research, 12, 15051515. doi:10.1002/aur.2155

Adams, D., Clark, M., \& Simpson, K. (2020). The relationship between child anxiety and the quality of life of children, and parents of children, on the autism spectrum. Journal of Autism and Developmental Disabilities, 50, 1756-1769. doi:10.1007/s10803-019-03932-2

Adams, D., \& Emerson, L. M. (2020). Family accommodation of anxiety in a community sample of children on the autism spectrum. Journal of Anxiety Disorders, 70, 102192. Doi: 10.1016/j.janxdis.2020.102192

Adams, D., Simpson, K., \& Keen, D. (2018). School-related anxiety symptomatology in a community sample of primary-school aged on the autism spectrum. Journal of School Psychology, 70, 64-73. doi:10.1016/j.jsp.2018.07.003

Adams, D., Young, K., \& Keen, D. (2019). Anxiety in children with autism at school: A systematic review. Review Journal of Autism and Developmental Disabilities, 6, 274-288. doi:10.1007/s40489-019-00172-z

Adams, D., Young, K., Simpson, K., \& Keen, D. (2018). Parent descriptions of the presentation and management of anxiousness in children on the autism spectrum. Autism, 23(4), 980-992. doi:10.1177/1362361318794031

American Psychiatric Association. (2013). Diagnostic and statistical manual of mental disorders $\left(5^{\text {th }}\right.$ ed.). Arlington, VA: American Psychiatric Association.

Baio, J., Wiggins, L., Christensen, D. L., Maenner, M. J., Daniels, J., Warren, Z., Kurzius-Spencer, M., Zahorodny, W., Rosenberg, C. R., White, T., Durkin, M. S., Imm, P., Nikolaou, L., Yeargin-Allsopp, M., Lee, L-C., Harrington, R., Lopez, M., Fitzgerald, R. T., Hewitt, A., ... Dowling, N. F. (2018). Prevalence of autism spectrum disorder among children aged 8 years - Autism and Developmental Disabilities Monitoring Network, 11 Sites, United States, 2014. 
Morbidity and mortality weekly report. Surveillance summaries (Washington, DC: 2002), 67(6), 1-23. doi:10.15585/mmwr.ss6706a1

Birmaher, B., Brent, D. A., Chiappetta, L., Bridge, J., Monga, S., \& Baugher, M. (1999). Psychometric properties of the Screen for Child Anxiety Related Emotional Disorders (SCARED): A replication study. Journal of the American Academy of Child \& Adolescent Psychiatry, 38(10), 1230-1236. doi:10.1097/00004583-199910000-00011

Boulter, C., Freeston, M., South, M., \& Rodgers, J. (2014). Intolerance of uncertainty as a framework for understanding anxiety in children and adolescents with autism spectrum disorders. Journal of Autism and Developmental Disorders, 44(6), 1391-1402. doi:10.1007/s10803-013-2001-x

Buhr, K., \& Dugas, M. J. (2006). Investigating the construct validity of intolerance of uncertainty and its unique relationship with worry. Journal of Anxiety Disorders, 20(2), 222-236.

Chesnut, S. R., Wei, T., Barnard-Brak, L., \& Richman, D. M. (2017). A meta-analysis of the social communication questionnaire: Screening for autism spectrum disorder. Autism, 21, 920-928. doi: $10.1177 / 1362361316660065$

Chorpita, B. F., Yim, L., Moffitt, C., Umemoto, L. A., \& Francis, S. E. (2000). Assessment of symptoms of DSM-IV anxiety and depression in children: A revised child anxiety and depression scale. Behaviour Research and Therapy, 38(8), 835-855. doi:10.1016/s00057967(99)00130-8

Conner, C. M., Maddox, B. B., \& White, S. W. (2013). Parents' state and trait anxiety: Relationships with anxiety severity and treatment response in adolescents with autism spectrum disorders. Journal of Atism and Developmental Disorders, 43(8), 1811-1818. Doi: $10.1007 / \mathrm{s} 10803-012-1728-0$

Creswell, C., Willetts, L., Murray, L., Singhal, M., \& Cooper, P. (2008). Treatment of child anxiety: An exploratory study of the role of maternal anxiety and behaviours in treatment outcome. 
Clinical Psychology \& Psychotherapy: An International Journal of Theory \& Practice, 15(1), 38-44. doi:10.1002/cpp.559

de Lijster, J. M., Dieleman, G. C., Utens, E. M., Dierckx, B., Wierenga, M., Verhulst, F. C., \& Legerstee, J. S. (2018). Social and academic functioning in adolescents with anxiety disorders: A systematic review. Journal of Affective Disorders, 230, 108-117. doi:10.1016/j.jad.2018.01.008

den Houting, J., Adams, D., Roberts, J., \& Keen, D. (2018a). An exploration of autism-specific and non-autism-specific measures of anxiety symptomatology in school-aged autistic children. Clinical Psychologist, 23 (3), 237-248. doi:10.1111/cp.12174

den Houting, J., Adams, D., Roberts, J., \& Keen, D. (2018b). Exploring anxiety symptomatology in school-aged autistic children using an autism-specific assessment. Research in Autism Spectrum Disorders, 50, 73-82. doi:10.1016/j.rasd.2018.03.005

den Houting, J., Adams, D., Roberts, J., \& Keen, D. (2020). Brief Report: Investigating the Impact of Anxious Symptomatology in Autistic Children. International Journal of Disability, Development and Education, ePub ahead of print. doi: 10.1080/1034912X.2020.1727420 DiPerna, J. C., \& Elliott, S. N. (2002). Promoting academic enablers to improve student achievement: An introduction to the mini-series. School Psychology Review, 31(3), 293-297.

Escovar, E. L., Drahota, A., Hitchcock, C., Chorpita, B. F., \& Chavira, D. A. (2019). Vicarious improvement among parents participating in child-focused cognitive-behavioral therapy for anxiety. Child \& Family Behavior Therapy, 41(1), 16-31. doi:10.1080/07317107.2019.1571770

Factor, R., Ryan, S., Farley, J., Ollendick, T., \& Scarpa, A. (2017). Does the presence of anxiety and ADHD symptoms add to social impairment in children with autism spectrum disorder? Journal of Autism \& Developmental Disorders, 47(4), 1122-1134. doi:10.1007/s10803-0163025-9 
Falk, N. H., Norris, K., \& Quinn, M. G. (2014). The factors predicting stress, anxiety and depression in the parents of children with autism. Journal of Autism and Developmental Disorders, 44(12), 3185-3203. doi:10.1007/s10803-014-2189-4

Freeston, M. H., Rhéaume, J., Letarte, H., Dugas, M. J., \& Ladouceur, R. (1994). Why do people worry? Personality and Individual Differences, 17(6), 791-802. Doi:10.1016/01918869(94)90048-5

Ghandour, R. M., Sherman, L. J., Vladutiu, C. J., Ali, M. M., Lynch, S. E., Bitsko, R. H., \& Blumberg, S. J. (2019). Prevalence and treatment of depression, anxiety, and conduct problems in US children. The Journal of Pediatrics, 206, 256-267. doi:10.1016/j.jpeds.2018.09.021

Gurmankin Levy, A., Maselko, J., Bauer, M., Richman, L., \& Kubzansky, L. (2007). Why do people with an anxiety disorder utilize more nonmental health care than those without? Health Psychology, 26(5), 545. doi:10.1037/0278-6133.26.5.545

Henry, J. D., \& Crawford, J. R. (2005). The short-form version of the Depression Anxiety Stress Scales (DASS-21): Construct validity and normative data in a large non-clinical sample. British Journal of Clinical Psychology, 44(2), 227-239. doi:10.1348/014466505X29657

Hodgson, A. R., Freeston, M. H., Honey, E., \& Rodgers, J. (2017). Facing the unknown: Intolerance of uncertainty in children with autism spectrum disorder. Journal of Applied Research in Intellectual Disabilities, 30(2), 336-344. doi:10.1111/jar.12245

Hwang, Y. I., Arnold, S., Srasuebkul, P., \& Trollor, J. (2019). Understanding anxiety in adults on the autism spectrum: An investigation of its relationship with intolerance of uncertainty, sensory sensitivities and repetitive behaviours. Autism, 24(2), 411-422. doi:10.1177/1362361319868907

Jackson, L., Keville, S., \& Ludlow, A. K. (2020). Mothers' experiences of accessing mental health care for their child with an autism spectrum disorder. Journal of Child and Family Studies, 29(2), 534-545. doi:10.1007/s10826-019-01662-8 
Keen, D., Adams, D., Simpson, K., den Houting, J., \& Roberts, J. (2019). Anxiety-related symptomatology in young children on the autism spectrum. Autism, 23(2), 350-358. doi:10.1177/1362361317734692

Keen, D., Webster, A., \& Ridley, G. (2016). How well are children with autism spectrum disorder doing academically at school? An overview of the literature. Autism, 20(3), 276-294. doi:10.1177/1362361315580962

Kerns, C., \& Kendall, P. C. (2012). The presentation and classification of anxiety in autism spectrum disorder. Clinical Psychology: Science and Practice, 19, 323-347. doi:10.1111/cpsp.12009

Kerns, C. M., Kendall, P. C., Zickgraf, H., Franklin, M., Miller, J., \& Herrington, J. (2015). Not to be overshadowed or overlooked: Functional impairments associated with comorbid anxiety disorders in youth with ASD. Behavior Therapy, 46, 29-39. doi:10.1016/j.beth.2014.03.005

Kester, K. R., \& Lucyshyn, J. M. (2018). Cognitive behavior therapy to treat anxiety among children with autism spectrum disorders: A systematic review. Research in Autism Spectrum Disorders, 52, 37-50. doi:10.1016/j.rasd.2018.05.002

Kyu, H. H., Pinho, C., Wagner, J. A., Brown, J. C., Bertozzi-Villa, A., Charlson, F. J., Coffeng, L.E., Dandona, L., Erskine, H.E., Ferrari, A.J., Fitzmaurice, C., Fleming, T.D., Forouzanfar, M.H., Graetz, N., Guinovart, C., Haagsma, J., Higashi, H., Kassebaum, N.J., Larson, H.J., ... Fitzmaurice, C. (2016). Global and national burden of diseases and injuries among children and adolescents between 1990 and 2013: Findings from the global burden of disease 2013 study. JAMA Pediatrics, 170(3), 267-287. doi:10.1001/jamapediatrics.2015.4276

Lang, R., Regester, A., Lauderdale, S., Ashbaugh, K., \& Haring, A. (2010). Treatment of anxiety in autism spectrum disorders using cognitive behaviour therapy: A systematic review. Developmental Neurorehabilitation, 13(1), 53-63. doi:10.3109/17518420903236288

Lovibond, P. F., \& Lovibond, S. H. (1995). The structure of negative emotional states: Comparison of the Depression Anxiety Stress Scales (DASS) with the Beck Depression and Anxiety 
Inventories. Behaviour Research and Therapy, 33(3), 335-343. doi:10.1016/00057967(94)00075-u

Lyneham, H. J., Sburlati, E. S., Abbott, M. J., Rapee, R. M., Hudson, J. L., Tolin, D. F., \& Carlson, S. E. (2013). Psychometric properties of the child anxiety life interference scale (CALIS). Journal of Anxiety Disorders, 27(7), 711-719. doi:10.1016/j.janxdis.2013.09.008

Maddox, B. B., Crabbe, S., Beidas, R. S., Brookman-Frazee, L., Cannuscio, C. C., Miller, J. S., Nicolaidis, C., \& Mandell, D. S. (2019). “I wouldn’t know where to start”: Perspectives from clinicians, agency leaders, and autistic adults on improving community mental health services for autistic adults. Autism, 24(4), 929-930. doi:10.1177/1362361319882227

Maisel, M. E., Stephenson, K. G., South, M., Rodgers, J., Freeston, M. H., \& Gaigg, S. B. (2016). Modeling the cognitive mechanisms linking autism symptoms and anxiety in adults. Journal of Abnormal Psychology, 125(5), 692. doi:10.1037/abn0000168

McVey, A. J., Schiltz, H. K., Haendel, A. D., Dolan, B. K., Willar, K. S., Pleiss, S. S., Karst, J. S., Carlson, M., Krueger, W., Murphy, C. C., Casnar, C. L., Yund, B., \& Van Hecke, A. V. (2018). Social difficulties in youth with autism with and without anxiety and adhd symptoms. Autism Research. doi:10.1002/aur.2039

Morgan, A. J., Rapee, R. M., \& Bayer, J. K. (2016). Prevention and early intervention of anxiety problems in young children: A pilot evaluation of Cool Little Kids Online. Internet Interventions, 4, 105-112. doi:10.1016/j.invent.2016.05.001

Neil, L., Olsson, N. C., \& Pellicano, E. (2016). The relationship between intolerance of uncertainty, sensory sensitivities, and anxiety in autistic and typically developing children. Journal of Autism and Developmental Disorders, 46(6), 1962-1973. doi:10.1007/s10803-016-2721-9

Osmanağaoğlu, N., Creswell, C., \& Dodd, H. F. (2018). Intolerance of uncertainty, anxiety, and worry in children and adolescents: A meta-analysis. Journal of Affective Disorders, 225, 8090. doi:10.1016/j.jad.2017.07.035 
Oswald, T. M., Beck, J. S., Iosif, A. M., McCauley, J. B., Gilhooly, L. J., Matter, J. C., \& Solomon, M. (2016). Clinical and cognitive characteristics associated with mathematics problem solving in adolescents with autism spectrum disorder. Autism Research, 9(4), 480-490. doi:10.1002/aur.1524

Ozsivadjian, A., Knott, F., \& Magiati, I. (2012). Parent and child perspectives on the nature of anxiety in children and young people with autism spectrum disorders: A focus group study. Autism, 16, 107-121. doi:10.1177/1362361311431703

Reaven, J., Washington, L., Moody, E. J., Stern, J. A., Hepburn, S. L., \& Blakeley-Smith, A. (2015). Examining the relationship between parental anxiety and treatment response in children and adolescents with autism spectrum disorder and anxiety. Journal of Autism and Developmental Disorders, 45(8), 2464-2473. doi:10.1007/s10803-015-2410-0

Rodgers, J., Goodwin, J., Parr, J. R., Grahame, V., Wright, C., Padget, J., Garland, D., Osborne, M., Labus, M., Kernohan, A., \& Freeston, M. (2019). Coping with Uncertainty in Everyday Situations (CUESC) to address intolerance of uncertainty in autistic children: Study protocol for an intervention feasibility trial. Trials, 20(1), 385. doi:10.1186/s13063-019-3479-0

Rodgers, J., Hodgson, A., Shields, K., Wright, C., Honey, E., \& Freeston, M. (2017). Towards a treatment for intolerance of uncertainty in young people with autism spectrum disorder: Development of the coping with uncertainty in everyday situations (CUESC) programme. Journal of Autism and Developmental Disorders, 47(12), 3959-3966. doi:10.1007/s10803016-2924-0

Rodgers, J., Wigham, S., McConachie, H., Freeston, M., Honey, E., \& Parr, J. R. (2016). Development of the anxiety scale for children with autism spectrum disorder (ASC-ASD). Autism Research, 9, 1205-1215. doi:10.1002/aur.1603

Rodgers J., Wigham S., McConachie H., et al. (nd) Anxiety Scale for Children - Autism Spectrum Disorder (ASC-ASD): Guidelines for use. 
Rutter, M., Bailey, A., \& Lord, C. (2003). The social communication questionnaire: Manual. Los Angeles, CA: Western Psychological Services.

Schnabel, A., Youssef, G. J., Hallford, D. J., Hartley, E. J., McGillivray, J. A., Stewart, M., forbes, D., \& Austin, D. W. (2020). Psychopathology in parents of children with autism spectrum disorder: A systematic review and meta-analysis of prevalence. Autism, 24(1), 26-40. doi:10.1177/1362361319844636

Silverman, W. K., \& Albano, A. M. (1996). The Anxiety Disorders Interview Schedule for DSM-IV: Child and parent versions. San Antonio, TX: Graywind.

Simpson, K., Adams, D., Wheeley, E., \& Keen, D. (2020). Parent perspectives on the presentation, triggers, impact, and support of anxiety in young children on the autism spectrum. Journal of Child and Family Studies, 29, 572-582. doi:10.1007/s10826-019-01576-5

Smith, I. C., Ollendick, T. H., \& White, S. W. (2019). Anxiety moderates the influence of ASD severity on quality of life in adults with ASD. Research in Autism Spectrum Disorders, 62, 39-47. doi:10.1016/j.rasd.2019.03.001

South, M., \& Rodgers, J. (2017). Sensory, emotional and cognitive contributions to anxiety in autism spectrum disorders. Frontiers in Human Neuroscience, 11(20), 1-7. doi:10.3389/fnhum.2017.00020

Spence, S. H. (1998). A measure of anxiety symptoms among children. Behaviour Research and Therapy, 36(5), 545-566. doi:10.1016/s0005-7967(98)00034-5

Strang, J. F., Kenworthy, L., Daniolos, P., Case, L., Wills, M. C., Martin, A., \& Wallace, G. L. (2012). Depression and anxiety symptoms in children and adolescents with autism spectrum disorders without intellectual disability. Research in Autism Spectrum Disorders, 6(1), 406412. doi:10.1016/j.rasd.2011.06.015

Toscano, R., Baillie, A. J., Lyneham, H. J., Kelly, A., Kidd, T., \& Hudson, J. L. (2020). Assessment of anxiety in children and adolescents: A comparative study on the validity and reliability of the Spence Children's Anxiety Scale in children and adolescents with anxiety and autism 
spectrum disorder. Journal of Affective Disorders, 260, 569-576.

doi:10.1016/j.jad.2019.09.055

Ung, D., Selles, R., Small, B. J., \& Storch, E. A. (2015). A systematic review and meta-analysis of cognitive-behavioral therapy for anxiety in youth with high-functioning autism spectrum disorders. Child Psychiatry \& Human Development, 46(4), 533-547. doi:10.1007/s10578014-0494-y

van Steensel, F. J., Bogels, S. M., \& Perrin, S. (2011). Anxiety disorders in children and adolescents with autistic spectrum disorders: A meta-analysis. Clinical Child and Family Psychology Review, 14, 302-317. doi:10.1007/s10567-011-0097-0

van Steensel, F. J., Bögels, S. M., \& Dirksen, C. D. (2012). Anxiety and quality of life: clinically anxious children with and without autism spectrum disorders compared. Journal of Clinical Child \& Adolescent Psychology, 41(6), 731-738. doi: 10.1080/15374416.2012.698725 van Steensel, F. J., Deutschman, A. A., \& Bögels, S. M. (2013). Examining the Screen for Child Anxiety-Related Emotional Disorder-71 as an assessment tool for anxiety in children with high-functioning autism spectrum disorders. Autism, 17(6), 681-692. Retrieved from https://doi.org/10.1177/1362361312455875

van Steensel, F. J., \& Heeman, E. J. (2017). Anxiety levels in children with autism spectrum disorder: A meta-analysis. Journal of Child and Family Studies, 26(7), 1753-1767. doi:10.1007/s10826-017-0687-7

Varni, J. W., Seid, M., \& Kurtin, P. S. (2001). PedsQL 4.0: Reliability and validity of the Pediatric Quality of Life Inventory version 4.0 generic core scales in healthy and patient populations. Medical Care, 39(8), 800-812. doi: 10.1097/00005650-200108000-00006

Vasa, R. A., Kalb, L., Mazurek, M., Kanne, S., Freedman, B., Keefer, A., Clemons, T., \& Murray, D. (2013). Age-related differences in the prevalence and correlates of anxiety in youth with autism spectrum disorders. Research in Autism Spectrum Disorders, 7(11), 1358-1369. doi:10.1016/j.rasd.2013.07.005 
Vasa, R. A., Keefer, A., Reaven, J., South, M., \& White, S. W. (2018). Priorities for advancing research on youth with autism spectrum disorder and co-occurring anxiety. Journal of Autism and Developmental Disorders, 48(3), 925-934. doi: 10.1007/s10803-017-3320-0

Wan, M. W., Green, J., Elsabbagh, M., Johnson, M., Charman, T., Plummer, F., \& BASIS Team. (2012). Parent-infant interaction in infant siblings at risk of autism. Research in Developmental Disabilities, 33(3), 924-932. doi:10.1016/j.ridd.2011.12.011

Wood, J. (2006). Effect of anxiety reduction on children's school performance and social adjustment. Developmental Psychology, 42(2), 345. doi:10.1037/0012-1649.42.2.345

Woodward, L. J., \& Fergusson, D. M. (2001). Life course outcomes of young people with anxiety disorders in adolescence. Journal of the American Academy of Child \& Adolescent Psychiatry, 40(9), 1086-1093. doi:10.1097/00004583-200109000-00018 